\title{
DEFORMATION BEHAVIOUR OF GELLAN GUM BASED ARTIFICIAL BONE STRUCTURES UNDER SIMULATED PHYSIOLOGICAL CONDITIONS
}

\author{
Nela KrČmáŘováa, ${ }^{a *}$ Jan ŠleichrT ${ }^{a}$, Tomáš Fíla ${ }^{b}$, Petr Koudelka $^{b}$, \\ DANIEL KYTÝř ${ }^{b}$
}

${ }^{a}$ Czech Technical University in Prague, Faculty of Transportation Sciences, Department of Mechanics and Materials, Konviktská 20, 12000 Prague 1, Czech Republic

${ }^{b}$ Institute of Theoretical and Applied Mechanics AS CR, v.v.i., Prosecká 76, 19000 Prague 9, Czech Republic

* corresponding author: krcmarova@fd.cvut.cz

\begin{abstract}
The paper deals with investigation of deformation behaviour of gellan gum (GG) based structures prepared for regenerative medicine purposes. Investigated material was synthesized as porous spongy-like scaffold reinforced by bioactive glass (BAG) nano-particles in different concentrations. Deformation behavior was obtained employing custom designed experimental setup. This device equipped with bioreactor chamber allows to test the delivered samples under simulated physiological conditions with controlled flow and temperature. Cylindrical samples were subjected to uniaxial quasi-static loading in tension and compression. Material properties of plain GG scaffold and reinforced scaffold buffered by $50 \mathrm{wt} \%$ and $70 \mathrm{wt} \%$ BAG were derived from a set of tensile and compression tests. The results are represented in form of stress-strain curves calculated from the acquired force and displacement data.
\end{abstract}

KEYWORDS: gellan gum scaffold, reinforcement, uni-axial loading, simulated physiological conditions.

\section{INTRODUCTION}

The worldwide incidence of bone disorders and conditions have trended steeply upward. Especially high income regions are expected twofold increase between 2010 and 2020 [1. This is the tribute for populations aging coupled with improper nutrient consumption and poor physical activity. Globally more than $40 \%$ of women and $30 \%$ of men are at increased risk of emergence of bone disorders [2]. Annually in the USA only, more than half a million bone defects are reported. Worldwide the treatment cost reaches more than $\$ 2.5$ billion.

The bone disorders treatment using engineered bone tissue has been viewed promising and yet not fully exploited potential alternative to conventional use of autografts and allografts. Artificial tissue is overcoming problems with donor site morbidity, loss of bone inductive factors and/or resorption during healing [3]. In general, several essential demands are placed on artificial structure: i) chemical biocompatibility without toxic effect ii) reduction of the stress shielding effect iii) successful diffusion of nutrients and oxygen iv) controlled degradation and resorption [4].

Presented paper deals with uni-axial quasi-static testing of artificial spongy-like structure [5] proposed for bone tissue engineering purposes as a bone scaffold. The investigated gellan gum - bioactive glass (GG$\mathrm{BAG}$ ) material combines organic (polysaccharitic) component with inorganic (Silicon-Calcium based) nanoparticles. This approach effectively enables for adaptation of physical and mechanical properties of the synthesized material according to the desired application [6]. The studied material was subjected to quasi-static loading in both tension and compression to evaluate its expected deformation response in interaction with human body. Therefore the experiment was carried out under simulated physiological conditions using bioreactor with circulating synthetic plasma.

\section{MATERIAL}

Bioactive-glass-reinforced gellan-gum is a promising material for wide use in bone tissue engineering [7]. Originally the Gellan-gum (microbial extracted polysaccharide) was used in food and pharmaceutical industry [8]. GG is composed of repeating units consisting of two D-glucose and one of each Lrhamnose and D-glucuronic acid [9]. Its main advantage is in ability to form highly porous $3 \mathrm{D}$ structures when properly cross-linked and fabricated [10].

Material investigated in this study was synthesized at Jozef Stefan Institute (Slovenia) as porous spongylike structure buffered by bioactive glass (BAG) nanoparticles [11]. During the production process gellan gum was dissolved in ultra-pure water by heating the solution for 30 minutes at $90{ }^{\circ} \mathrm{C}$. To the hot GG solution a dispersion of BAG was admixed and $0.18 \mathrm{wt} \%$ $\mathrm{CaCl}_{2}$ was added. Kept at high temperatures this mixture was then poured into required mould and let there to spontaneously jellify. Finally the samples were frozen at $-80^{\circ} \mathrm{C}$ and freeze-dried. 


\section{Methods}

For initial awareness about deformation characteristics of synthesized material set of quasi-static experiments was performed. The first goal was to demonstrate possibilities of in house developed experimental infrastructure for this purpose. Expected collapse forces was in range of single newtons and precise loading plate positioning was required as well. To obtain more relevant results some modifications of the experimental devices in detail presented in 3.2 was carried out. Using this adapted devices basic material properties and stress-strain response were obtained.

\subsection{EXPERIMENTAL PROCEDURE}

Cylindrical samples with height $h=8.6 \pm 0.4 \mathrm{~mm}$, diameter $d=5.0 \pm 0.1 \mathrm{~mm}$ and weight $m \approx 11 \mathrm{mg}$, $\approx 16 \mathrm{mg}$ and $\approx 24 \mathrm{mg}$ for plain GG scaffold, GGBAG reinforced scaffold with $50 \mathrm{wt} \%$ and $70 \mathrm{wt} \%$ BAG respectively were subjected to tensile and compressive loading under wet condition. For wet condition simulating physiological environment of human body infusion solution Plasmalyte (Bartex, Czech Republic) was used. Loading plate displacement was set typically for $1000 \mu \mathrm{m}$ corresponding to deformation approx. $11-12 \%$ sufficient for significant sample damage. Loading rate was set to $2 \mu \mathrm{ms}^{-1}$. Force and position was read-out with sampling frequency $50 \mathrm{sps}$.

\subsection{INSTRUMENTATION}

In house developed indentation device for low-force indentation was adapted for tensile and compression test. Originally the device was designed using modular aluminum profile $(30 \times 30 \mathrm{~mm})$ frame bearing i) $\mathrm{X}$ and $\mathrm{Y}$ motorized axis KK40 (HIWIN, Japan) for sample positioning with repeatability $10 \mu \mathrm{m}$ ii) indentation axis based on linear stage MGW12 (HIWIN, Japan) and linear actuator 43 series (Haydon Kerk, USA) with position accuracy $3 \mu \mathrm{m}$ and mounting for U9B/C series (HBM, Germany) load-cell. This axis was upgraded using the linear actuator with position accuracy $1.5 \mu \mathrm{m}$, encoder with resolution $0.5 \mu \mathrm{m}$ and load cell with nominal force $50 \mathrm{~N}$ (the most precise force transducer in U9B/C series). For testing under wet condition testing device was equipped with bioreactor with controlled flow and temperature of circulating fluid. From the heated reservoir is the fluid pumped to the basin surrounding the samples and loading plates.

\subsection{Strain CALCUlation}

The investigated material exhibits very low stiffness, which, coupled with high porosity and suboptimal geometry of the samples, induces high potential for significant boundary effects. Unfortunately full-field optical strain measurement of the wet samples placed in fluid basin was not possible using the available setup. Therefore comparative measurements for contact and contactless strain evaluation methods was performed in previous studies [12, 13]. However production process of the GG-BAG samples does not allow to reliably produce cylindrical samples, the diameter of specimens varied in average $\pm 100 \mu \mathrm{m}$, and the loaded faces were rough and not plan-parallel strain-stress curve derived directly from force transducer and encoder indicate relevant results.

\subsection{Stress CAlCulation}

The stress $\sigma$ in all experimental analysis was considered as engineering stress obtained using

$$
\sigma=\frac{F}{A_{c}}
$$

where $A_{c}$ is cross-sectional area of the specimen calculated from minimal sample diameter measured before deformation. Force $F$ was acquired by the load-cell. For the purpose of stress calculations, samples were considered ideally cylindrical, neglecting all geometrical irregularities.

\section{Results}

Material properties and deformation behaviour of plain GG scaffold and GG-BAG reinforced scaffold with $50 \mathrm{wt} \%$ and $70 \mathrm{wt} \%$ BAG content were studied in tensile and compression tests under dry and wet conditions. Five experiments for each type of material and loading mode were performed. Young's modulus was calculated using linear regression applied on the elastic part of stress-strain diagrams. The calculated elastic properties and yield stresses are listed in Tabs. 26 .

\begin{tabular}{|c|c|}
\hline sample & $E[\mathrm{kPa}]$ \\
GG00 1 & $88.588 \pm 0.147$ \\
GG00 2 & $119.507 \pm 0.156$ \\
GG00 3 & $126.159 \pm 0.142$ \\
GG00 4 & $93.571 \pm 0.144$ \\
GG00 5 & $141.089 \pm 0.146$ \\
GG00 mean & $113.783 \pm 22.219$ \\
\hline
\end{tabular}

TABLE 1. Elastic properties of plain GG samples for compression test

\begin{tabular}{|c|c|}
\hline sample & $E[\mathrm{kPa}]$ \\
GG00 1 & $56.343 \pm 0.843$ \\
GG00 2 & $33.403 \pm 0.209$ \\
GG00 3 & $36.383 \pm 0.412$ \\
GG00 4 & $69.077 \pm 0.945$ \\
GG00 5 & $70.436 \pm 0.951$ \\
GG00 mean & $53.129 \pm 17.562$ \\
\hline
\end{tabular}

TABLE 2. Elastic properties of plain GG samples for tensile test 


\begin{tabular}{|c|c|}
\hline sample & $E[\mathrm{kPa}]$ \\
GG50 1 & $81.4518 \pm 0.145$ \\
GG50 2 & $131.882 \pm 0.137$ \\
GG50 3 & $70.8462 \pm 0.141$ \\
GG50 4 & $113.892 \pm 0.281$ \\
GG50 5 & $140.221 \pm 0.201$ \\
GG50 mean & $107.659 \pm 30.528$ \\
\hline
\end{tabular}

TABLE 3. Elastic properties of GG samples with $50 \mathrm{wt} \%$ BAG for compression test

\begin{tabular}{|c|c|}
\hline sample & $E[\mathrm{kPa}]$ \\
GG50 1 & $24.406 \pm 0.090$ \\
GG50 2 & $27.156 \pm 0.085$ \\
GG50 3 & $24.287 \pm 0.080$ \\
GG50 4 & $23.719 \pm 0.081$ \\
GG50 5 & $21.376 \pm 0.089$ \\
GG50 mean & $24.18 \pm 2.061$ \\
\hline
\end{tabular}

TABLE 4. Elastic properties of GG samples with $50 \mathrm{wt} \%$ BAG for tensile test

\begin{tabular}{|c|c|}
\hline sample & $E[\mathrm{kPa}]$ \\
GG70 1 & $134.424 \pm 0.120$ \\
GG70 2 & $63.566 \pm 0.077$ \\
GG70 3 & $79.592 \pm 0.078$ \\
GG70 4 & $67.376 \pm 0.083$ \\
GG70 5 & $65.131 \pm 0.077$ \\
GG70 mean & $82.018 \pm 29.967$ \\
\hline
\end{tabular}

TABLE 5. Elastic properties of GG samples with $70 \mathrm{wt} \%$ BAG for compression test

\begin{tabular}{|c|c|}
\hline sample & $E[\mathrm{kPa}]$ \\
GG70 1 & $22.7629 \pm 0.080$ \\
GG70 2 & $23.4423 \pm 0.082$ \\
GG70 3 & $20.9057 \pm 0.081$ \\
GG70 4 & $21.1495 \pm 0.101$ \\
GG70 5 & $22.7019 \pm 0.079$ \\
GG70 mean & $22.192 \pm 1.105$ \\
\hline
\end{tabular}

TABle 6. Elastic properties of GG samples with $70 \mathrm{wt} \%$ BAG for tensile test

All obtained results in form of enveloped stressstrain curves are plotted in Figs. 1, 2, The stressstrain area for each type of the scaffold represents minimum and maximum stress for each strain value.

\section{Conclusion}

GG-BAG samples with 0, 50 and $70 \mathrm{wt} \%$ fraction of reinforcing BAG particles were subjected to tensile and compressive loading test to evaluate deformation response in simulated physiological condition. It was found out, that the ambient environment has significant influence on mechanical response of the material as the measured properties. The scaffolds wetted by

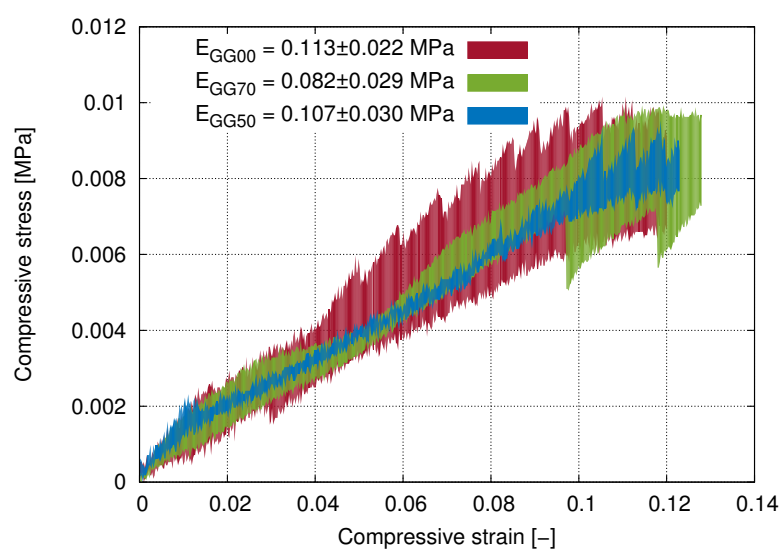

FiguRE 1. Stress-strain curves envelope of scaffolds under compressive loading

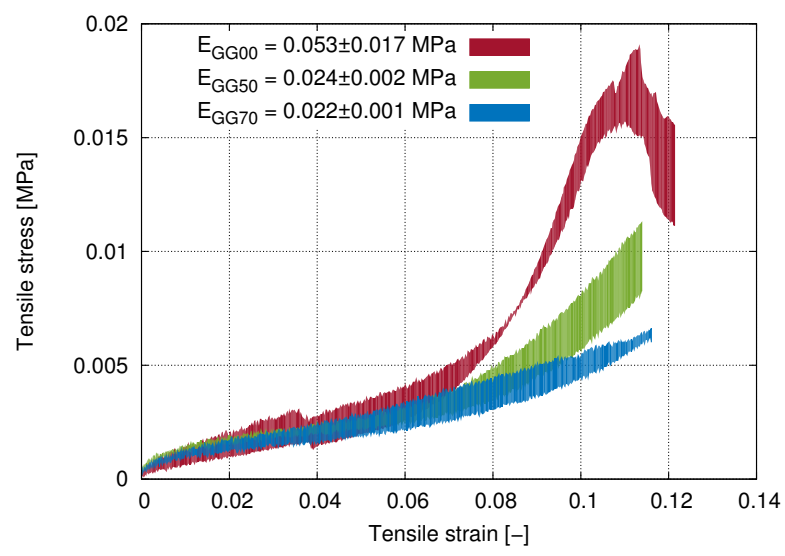

Figure 2. Stress-strain curves envelope of scaffolds under tensile loading

the synthetic plasma solution exhibited radical loss of stiffness, where the elastic modulae decreased more than ten times [12].

No significant reinforcement effect of BAG particles was observed during compression test. In case of tensile loading BAG buffered samples unexpectedly exhibited lower elastic modulae and ultimate stresses compared to the plain GG samples. That could be given by scaffold cell-wall heterogenity and disintegrity caused by rigid nature of glass particles.

It can be concluded that presented analysis proved use of the considered experimental methods together with available experimental infrastructure for the testing of GG based scaffolds. The most limiting part of the experimental setup is load-cell signal-to-noise ratio at desired loading level and generally suboptimal geometrical characteristics of the samples inducing shear stresses during loading.

\section{ACKNOWLEDGEMENTS}

The research was supported by Grant Agency of the Czech Technical University in Prague (grant no. SGS15/225/OHK2/3T/16), by InterReg project Com3dXCT (ATCZ38) and by institutional support RVO: 
68378297. We would like to express our special thanks to Ana Grantar for sample synthesization.

\section{REFERENCES}

[1] W. H. Organization. World health statistics. WHO Press, 2015.

[2] W. H. Organization. Global Recommendations on Physical Activity for Health. WHO Press, Switzerland, 2010.

[3] A. R. Vaccaro, K. Chiba, J. G. Heller, et al. Bone grafting alternatives in spinal surgery. The Spine Journal 2(3):206 - 215, 2002. DOI:10.1016/S1529-9430(02)00180-8

[4] A. R. Amini, C. T. Laurencin, S. P. Nukavarapu. Bone tissue engineering: Recent advances and challenges. Critical Reviews in Biomedical Engineering 40(5):363408, 2012. DOI:10.1615/CritRevBiomedEng.v40.i5.10

[5] L. Polo-Corrales, M. Latorre-Esteves, J. E. RamirezVick. Scaffold design for bone regeneration. Journal of nanoscience and nanotechnology 14(1):15-56, 2014.

[6] E. R. Morris, K. Nishinari, M. Rinaudo. Gelation of gellan - a review. Food Hydrocolloids 28(2):373 - 411, 2012. DOI:10.1016/j.foodhyd.2012.01.004

[7] M. Bououdina. Emerging Research on Bioinspired Materials Engineering. IGI Global, 2016. DOI:10.4018/978-1-4666-9811-6.
[8] D. Hoikhman, Y. Sela. Gellan gum based oral controlled release dosage forms- a novel platform technology for gastric retention, 2005. WO Patent App. PCT/IL2004/000,654.

[9] J. T. Oliveira, L. Martins, R. Picciochi, et al. Gellan gum: A new biomaterial for cartilage tissue engineering applications. Journal of Biomedical Materials Research Part A 93A(3):852-863, 2010. DOI:10.1002/jbm.a.32574

[10] N. Drnovšek, S. Novak, U. Dragin, et al. Bioactive glass enhances bone ingrowth into the porous titanium coating on orthopaedic implants. International Orthopaedics 36(8):1739-1745, 2012. DOI:10.1007/s00264-012-1520-y

[11] A. Gantar, L. Da Silva, J. Oliveira, et al. Nanoparticulate bioactive-glass-reinforced gellan-gum hydrogels for bone-tissue engineering. Materials Science and Engineering C 43:27-36, 2014. Cited By 13, DOI:10.1016/j.msec.2014.06.045

[12] D. Kytýř, T. Doktor, O. Jiroušek, et al. Deformation behaviour of a natural-shaped bone scaffold. Materiali in Tehnologije 50(3):301-305, 2016. Cited By 0, DOI:10.17222/mit.2014.190

[13] J. Šleichrt, M. Adorna, M. Neuhäuserová, et al. Deformation characteristics of chopped fibre composites subjected to quasi-static tensile loading. Acta Polytechnica CTU Proceedings 3:71-74, 2016. DOI:10.14311/APP.2016.3.0071 